УДК 616.89-008.454-053.6(571.6)(511):615.214:615.851.8

Для цитирования: Логинов И.П., Солодкая Е.В. Клинические характеристики депрессивных расстройств у подростков Дальнего Востока России и Северного Китая. Сибирский вестник психиатрии и наркологии. 2019; 2 (103): 108-112. https://doi.org/10.26617/1810-3111-2019-2(103)-108-112

\title{
Клинические характеристики депрессивных расстройств у подростков Дальнего Востока России и Северного Китая
}

\section{Логинов И.П., Солодкая Е.В.}

Дальневосточный государственньй медииинский университет

Россия, 680000, Хабаровск, ул. Муравьева-Амурского, 35

\section{PEЗЮME}

Целью исследования явилось определение клинических и социально-психологических закономерностей формирования структуры и динамики непсихотических депрессивных расстройств у подростков, проживающих на Дальнем Востоке России и в Китае. Материалом для решения поставленных задач послужили данные рандомизированного исследования 123 подростков, из них 61 подросток с симптомами депрессивного расстройства, проживающих в северно-китайской провинции Хэйлунцзян, и 62 подростка с депрессивной симптоматикой, проживающих на Дальнем Востоке России. Результаты. Проведенное транскультуральное исследование выявило значительное преобладание среди подростков с депрессивными расстройствами лиц женского пола в обеих этнических группах (российская группа - 78,0\%, китайская группа - 68,2\%). Установленная психопатологическая структура депрессивных расстройств показала неоднородность клинических проявлений в зависимости от возрастного периода подростков, что позволило отнести российских и китайских пациентов к двум возрастным периодам: подростки 11-14 лет (1-я группа, 20\% и 15,9\%) и подростки 1518 лет, на которых приходился пик депрессивных расстройств (2-я группа, 80,0\% и 84,1\%).

\section{Ключевые слова: транскультуральная психиатрия, подростки, депрессивные расстройства.}

\section{ВВЕДЕНИЕ}

По современным эпидемиологическим данным $[1,2]$, распространенность депрессий в популяции 15-20-летних колеблется от 8 до $20 \%$. Отмечается, что более $50 \%$ всей психической заболеваемости приходится на лиц подросткового и юношеского возрастов, а пик суицидов - на возрастную группу от 15 до 25 лет [3]. Проведенные исследования показывают, что аффективная патология представляет собой гетерогенную группу расстройств. Своевременная диагностика и терапия аффективных расстройств до сих пор представляет собой сложную клиническую задачу $[4,5]$. Проблема изучения психического здоровья с позиций раскрытия его специфических региональных и этнокультуральных особенностей диктует необходимость рассмотрения клинико-динамических параметров для отдельных групп населения и этносов [6].

\section{ЦЕЛЬ ИССЛЕДОВАНИЯ}

Определение клинических и социальнопсихологических закономерностей формирования структуры и динамики непсихотических депрессивных расстройств у подростков, проживающих в культурально различных странах - на Дальнем Востоке России и в Северном Китае, с целью разработки и внедрения модели дифференцированной профилактики подростковых депрессий.

\section{МАТЕРИАЛЫ И МЕТОДЫ}

Объектом исследования явились пациенты 11-18 лет, классифицируемые как ранние подростки (11-14 лет) и поздние подростки (15-18 лет), находившиеся на амбулаторном и стационарном лечении в КГБУЗ «Краевая психиатрическая больница» МЗ ХК и в Первом специальном госпитале г. Харбина (The First Special Hospital of Harbin) по поводу аффективных pacстройств, родители которых дали информированное согласие на участие в исследовании.

Достоверность результатов исследования подтверждается достаточным числом наблюдений в основной и контрольной группах, позволяющим проводить статистическую обработку и формулировать выводы. Статистическую обработку проводили с применением пакета прикладных программ STATISTICA 6.0.

Материалом для решения поставленных задач послужили данные рандомизированного исследования 123 пациента с симптомами депрессивного расстройства, из которых 61 - этнические китайцы, проживающие в севернокитайской провинции Хэйлунцзян и поступившие на стационарное лечение в 1-й специальный госпиталь г. Харбина, и 62 - российские подростки, проживающие на Дальнем Востоке, получавшие лечение в Хабаровской краевой психиатрической больнице. 


\section{ОБСУЖДЕНИЕ РЕЗУЛЬТАТОВ}

По результатам первоначального исследования выявлено отсутствие статистически достоверных различий между подростками российской и китайской групп по возрастному, половому составу, психопатологической отягощенности и соматоневрологической заболеваемости.

Всем пациентам, поступавшим в психиатрический стационар с симптомами депрессии, проводилось клинико-психопатологическое, экспериментально-психологическое и лабораторное обследование.

Проведенное транскультуральное исследование выявило значительное преобладание среди подростков с депрессивными расстройствами лиц женского пола в обеих этнических группах: российская группа $-78,0 \%$, китайская группа - 68,2\%.

Были сформированы две возрастные группы (11-14 и 15-18 лет). В первой возрастной группе (11-14 лет) среди российских и китайских подростков достоверных отличий в клиниконозологической структуре депрессивных расстройств не выявлено. Вместе с тем у российских подростков второй возрастной группы (15-18 лет) клинико-психопатологическая структура депрессивных расстройств достоверно чаще характеризовалась кратковременными (42\%) и пролонгированными (24\%) депрессивными реакциями, тогда как среди китайских подростков достоверно чаще встречался умеренный депрессивный эпизод (23\%) и тяжелый депрессивный эпизод без психотических симптомов $(41 \%)$.

На следующем этапе исследования было изучено распределение больных по клиникопсихопатологической структуре ведущего синдрома. Получены достоверные данные о структуре ведущего синдрома среди подростков второй возрастной группы (15-18 лет): у китайских подростков достоверно чаще выявлено преобладание астено-адинамического варианта депрессивных расстройств (36\%) в сравнении с российскими подростками.

В клиническом интервью китайские подростки отмечали, что прежние интересы и увлечения перестали играть в их жизни какуюлибо значимую роль, что переставали справляться с обычными повседневными нагрузками, а это влекло за собой снижение умственной и физической работоспособности и негативно сказывалось на качестве получаемых знаний и текущей успеваемости.
Как правило, подростки не связывали ухудшение настроения с актуальным психическим состоянием и пытались объяснить низкую успеваемость необоснованно растущими требованиями педагогов и родителей и недоброжелательным отношением со стороны окружающих. Часть пациентов (15\%) в подобной ситуации пытались справиться с учебными нагрузками, «взять себя в руки», «направить все силы на учебу», но неудачные попытки самостоятельно преодолеть школьную дезадаптацию только усиливали астенизацию и приводили к еще большему ухудшению настроения. Параллельно появлялись нарушения сна, ухудшался аппетит, резко снижался жизненный тонус в целом. Постепенно появлялись идеи самоуничижения и собственной никчемности, сниженная самооценка в силу неспособности быть «нормальным, полноценным человеком», что закономерно приводило к обострению депрессии.

В начале депрессивного эпизода многие пациенты, критически оценивая свое психическое состояние, всё же пытались справиться с ним самостоятельно. Только 5\% из них обращались к специалистам (психиатрам, психотерапевтам, психологам, участковым терапевтам). Преобладающее большинство подростков искали помощь у близких, но чаще всего не находили поддержки, так как ближайшее окружение воспринимало их жалобы как «неуместные», «непонятные», «навязчивые». Часто пациенты пытались справиться с депрессией, используя алкоголь и другие ПАВ, но это только ухудшало и без того тяжелое психическое состояние.

Вышеуказанные выводы подтверждаются полученными показателями по психологическим шкалам Гамильтона (HAMD-17, HARS). Так, в первой возрастной группе у $14 \%$ российских подростков состояние тревоги оценивалось как средне выраженное, тогда как во второй возрастной группе данный показатель возрастает до 42\%. Тревожное состояние, наблюдавшееся у $34 \%$ респондентов, клинически проявлялось переживанием выраженного чувства тревоги в ответ на возникновение даже незначительных по силе психогенных ситуаций. Эти опрошенные были отнесены к лицам с высоким уровнем ситуационной тревожности. Таким образом, 84,1\% от общего числа респондентов отличались высокими уровнями как личностной, так и ситуационной тревожности, что можно расценивать как их специфическую психологическую особенность, предрасполагающую к развитию суицидального поведения. 
Следующей задачей сравнительного исследования стала разработка терапевтической стратегии и системы превентивных мероприятий, позволяющей улучшить качество профилактической помощи подросткам с непсихотическими депрессивными расстройствами.

В ходе настоящего исследования был разработан прогностически-триггерный программный комплекс развития депрессивных расстройств по медико-социальным факторам риска. Дизайн исследования предполагал, что внедрение данного комплекса позволит улучшить качество оказываемой профилактической помощи подросткам с непсихотическими депрессивными расстройствами на основе включения в его структуру медикаментозной, психотерапевтической и психопревентивной составляющих. Этот комплекс построен в соответствии с классическими подходами к терапии депрессивных расстройств и суицидального процесса, а также с учетом индивидуальнопсихологических характеристик пациентов. При этом необходимо иметь в виду, что психофармакотерапия назначалась только в случае наличия у подростка тех или иных психических расстройств.

Согласно нашему опыту, наиболее эффективными средствами в психофармакотерапии расстройств депрессивного спектра являются антидепрессанты, среди которых наиболее предпочтительны селективные ингибиторы обратного захвата серотонина (СИОЗС). При этом мы отдавали себе отчет в том, что для детей и подростков до 15-летнего возраста в клинической практике в России разрешен к применению только феварин (с 8 лет), в то время как в КНР в инструкциях по применению лекарственных препаратов, включая антидепрессанты, нет возрастных ограничений. В психиатрических клиниках КНР антидепрессантами выбора для лечения детей и подростков являются флуоксетин, эсциталопрам, сертралин и венлафаксин, при этом предпочтению отдается первым двум. Антидепрессивная терапия дополнялась назначением транквилизаторов, нормотимиков, нейролептиков. Помимо медикаментозной терапии подросткам проводили психотерапию. При выборе методов психотерапии в отношении китайских и российских подростков предпочтение отдавалось арттерапевтическим и игровым методикам, обязательным компонентом была семейная терапия с позиции партнерских отношений в семье и применение методов когнитивноповеденческой психотерапии.
Основным принципом охраны психического здоровья детей и подростков является предупредительное (превентивное) направление. Известно, что применение современных информационных и математико-статистических методов может значительно повысить качество оказания как первичной, так и вторичной профилактики депрессивных расстройств.

С применением модели логистической регрессии Logistica $(\geq 2)$ у подростков российской группы было выявлено пять переменных статистически значимых факторов, вносящих вклад в формирование депрессивных расстройств: родительский прессинг, неблагоприятные отношения с одноклассниками, разногласия и непонимание с родителями, наследственная отягощенность психическими заболеваниями, преморбидные акцентуации личностных черт. Регрессионный анализ факторов риска депрессивных расстройств у подростков китайской группы доказал наличие статистически значимой корреляции с пессимистическими взглядами и планами на будущее, родительским прессингом, плохими условиями проживания, проблемами в отношениях с одноклассниками и родителями. Анализируя статистически значимые факторы риска депрессивных расстройств у подростков, мы определили те из них, которые можно использовать как бинарные вопросы для создания модели депрессивного поведения.

\section{ЗАКЛЮЧЕНИЕ}

Значимым мероприятием в алгоритме антидепрессивной терапии у подростков является раннее распознавание депрессий. В его основе должна лежать достаточная осведомленность врачей общесоматической сети о проявлениях депрессии, поскольку именно к ним на начальном этапе заболевания обращаются подростки и их родители. Поэтому большое значение играет качественная организация взаимодействия между психиатрической службой и учреждениями общемедицинской сети. Кроме того, знание этнокультуральной специфики заболеваний у представителей коренных дальневосточных этносов позволит достичь лучшего понимания механизмов формирования депрессивных расстройств. Выявленные клинические особенности позволят более дифференцированно и эффективно осуществлять профилактику, диагностику и лечение этой патологии, что внесет существенный вклад в улучшение психического здоровья подростков Дальнего Востока России и Северного Китая. 


\section{КОНФЛИКТ ИНТЕРЕСОВ}

Авторы заявляют об отсутствии возможных конфликтов интересов в связи с публикацией данной статьи.

\section{ИСТОЧНИК ФИНАНСИРОВАНИЯ}

Исследование имеет спонсорскую поддержку в форме гранта РФФИ в рамках научного проекта № 19-013-00018.

СООТВЕТСТВИЕ ПРИНЦИПАМ ЭТИКИ

Исследование было проведено с соблюдением норм современной биомедицинской этики и этических стандартов, разработанных в соответствии с Хельсинской декларацией BMA (Протокол заседания этического комитета Дальневосточного государственного медицинского университета № 3 от 05.02.2018 г.).

\section{ЛИТЕРАТУРА}

1. Wong J.P.S., Stewart S.M., Claassen C., Lee P.W.H, Rao U., Lam T.H. Repeat suicide attempts in Hong Kong community adolescents. Social Science and Medicine. 2008, 66: 232-241. https://doi.org/10.1016/j.socscimed.2007.08.031
2. Yunming L., Changsheng C., Haibo T., Wenjun C., Shanhong F., Yan M., Yongyong X., Qianzhen H. Prevalence and risk factors for depression in older people in Xi' an China: a community-based study. Int J Geriatr Psychiatry. 2012 Jan; 27 (1): 31-39. doi: 10.1002/gps.2685

3. Krasnov V.N. Diagnosis and classification of mental disorders in Russian speaking psychiatry: focus on affective spectrum disorders. European Psychiatry. 2011; 26 (2): 11-14.

4. Краснов В.Н., Алфимова М.В., Мельникова Т.С., Фролов А.М. Взаимосвязи когнитивных и эмоциональных нарушений при депрессиях (обзор литературы). Доктор.Ру. 2013.5 (83): 70-76.

5. Куприянова И.Е., Карауш И.С., Дроздовский Ю.В., Усов Г.М. Дети и подростки с сенсорными нарушениями: проблемы депрессии и суицидального риска. Суицидология. 2017; 8, 2 (27): $70-81$.

6. Семке В.Я., Бохан Н.А. Транскультуральная аддиктология. Томск : Изд-во Том. ун-та, 2008: 588.

Поступила в редакцию 11.02.2019 Утверждена к печати 8.04.2019

Логинов Игорь Павлович - доктор медицинских наук, профессор, заведующий кафедрой психиатрии и наркологии.

Солодкая Евгения Владимировна - аспирант кафедры психиатрии и наркологии.

Логинов Игорь Павлович, log-i-p1954@mail.ru

УДК 616.89-008.454-053.6(571.6)(511):615.214:615.851.8

For citation: Loginov I.P., Solodkaya E.V. Clinical characteristics of depressive disorders in adolescents in the Russian Far East and North China. Siberian Herald of Psychiatry and Addiction Psychiatry. 2019; 2 (103): 108-112. https://doi.org/10.26617/1810-3111-2019-2(103)-108-112

\section{Clinical characteristics of depressive disorders in adolescents in the Russian Far East and North China}

\section{Loginov I.P., Solodkaya E.V.}

Far Eastern State Medical University

Muravyev-Amursky Street 35, 680000, Khabarovsk, Russian Federation

\section{ABSTRACT}

The aim of the study was to determine the clinical and socio-psychological patterns of formation of the structure and dynamics of non-psychotic depressive disorders in adolescents living in the Russian Far East and in China. Material for solving the set tasks was given by data of a randomized study of 123 adolescents, 61 of them were adolescents with symptoms of depressive disorder living in the North China province of Heilongjiang, and 62 adolescents with depressive symptoms living in the Far East of Russia. Results. A transcultural study revealed a significant predominance among adolescents with depressive disorders of females in both ethnic groups (the Russian group $78.0 \%$, the Chinese group - 68.2\%). The established psychopathological structure of depressive disorders showed heterogeneity of clinical manifestations depending on the age of adolescents, which refers Russian and Chinese patients to two age periods: adolescents 11-14 years old (group 1, 20\% and 15.9\%) and adolescents 15-18 years old, which accounted for the peak of depressive disorders (group 2, 80.0\% and 84.1\%). 


\section{REFERENCES}

1. Wong J.P.S., Stewart S.M., Claassen C., Lee P.W.H, Rao U., Lam T.H. Repeat suicide attempts in Hong Kong community adolescents. Social Science and Medicine. 2008, 66: 232-241. https://doi.org/10.1016/j.socscimed.2007.08.031

2. Yunming L., Changsheng C., Haibo T., Wenjun C., Shanhong F., Yan M., Yongyong X., Qianzhen H. Prevalence and risk factors for depression in older people in Xi' an China: a community-based study. Int J Geriatr Psychiatry. 2012 Jan; 27 (1): 31-39. doi: 10.1002/gps.2685

3. Krasnov V.N. Diagnosis and classification of mental disorders in Russian speaking psychiatry: focus on affective spectrum disorders. European Psychiatry. 2011; 26 (2): 11-14.

4. Krasnov V.N., Alfimova M.V., Melnikova T.S., Frolov A.M. Vzaimosvyazi kognitivnyih i emotsionalnyih narusheniy pri depressiyah (obzor literaturyi) [The relationship of cognitive and emotional disorders in depression (review of literature)]. Doctor.Ru. 2013.5 (83): 70-76 (in Russian).

5. Kupriyanova I.E., Karaush I.S., Drozdovsky Yu.V., Usov G.M. Deti i podrostki s sensornyimi narusheniyami: problemyi depressii i suitsidalnogo riska [Children and adolescents with sensory disorders: problems of depression and suicidal risk]. Suitsidologiya - Suicidology. 2017; 8, 2 (27): 7081 (in Russian).

6. Semke V.Ya., Bokhan N.A. Transkul'tural'naya addiktologiya [Transcultural addictology]. Tomsk: Publishing House of Tomsk University, 2008: 588 (in Russian).

Received February 11.2019 Accepted April 08.2019

Loginov Igor P. - MD, Prof., Head of the Department of Psychiatry and Narcology Far Eastern State Medical University, Khabarovsk, Russian Federation.

Solodkaya Eugenia V. - graduate student of the Department of Psychiatry and Narcology Far Eastern State Medical University, Khabarovsk, Russian Federation.

Loginov Igor P., log-i-p1954@mail.ru 